\title{
Readmissions and repeat procedures after catheter ablation for atrial fibrillation
}

\author{
Grzegorz Opolski ${ }^{1}$, Łukasz Januszkiewicz ${ }^{1}$, Ewa Szczerba ${ }^{1}$, Bogusława Osińska ${ }^{2}$, \\ Daniel Rutkowski ${ }^{2}$, Zbigniew Kalarus ${ }^{3}$, Jarosław Kaźmierczak ${ }^{4}$ \\ ${ }^{1}$ Department of Cardiology, Medical University of Warsaw, Warsaw, Poland \\ ${ }^{2}$ National Health Fund, Warsaw, Poland \\ ${ }^{3}$ Department of Cardiology, Congenital Heart Disease and Electrotherapy, Silesian Medical University, \\ Silesian Centre for Heart Disease, Zabrze, Poland \\ ${ }^{4}$ Department of Cardiology, Pomeranian Medical University, Szczecin, Poland
}

\begin{abstract}
Background: The aim of this study was to assess the frequency of all-cause rehospitalization and due to atrial fibrillation/flutter $(A F / A F l)$, repeat ablation of $A F / A F l$, mortality within 30 days and 1-year follow-up in patients after $A F / A F l$ ablation procedure.

Methods: Using data from the National Health Fund we identified a database comprising 2,022 patients who underwent AF/AFl ablation between January, 2012 and December, 2012 in Poland. The primary endpoint was readmission to hospital with discharge diagnosis $A F / A F l$. The secondary endpoints included: repeat $A F / A F l$ ablation, cardiovascular hospitalization, all-cause hospitalization, all-cause mortality assessed in 30-day and 1-year time frame.

Results: The mean age was $58.6 \pm 10.9$ years $(66.8 \%$ male). The mean time of the index ablation hospitalization was $3.8 \pm 2.6$ days. After discharge, 123 (6.1\%) and $540(26.7 \%)$ patients were hospitalized because of $A F / A F l$ within 30 days and 1 year, respectively. During 1-year follow-up, 192 (9.5\%) patients underwent subsequent AF/AFl ablations. The patients that underwent the second ablation were younger (56.6 \pm 11.0 vs. $59.1 \pm 10.8 ; p=0.019)$ and the time of the index hospitalization was shorter (3.75 \pm 2.16 vs. $4.45 \pm 3.26 ; p=0.03)$. Within 30 days 194 (9.6\%) patients were hospitalized and 747 (36.9\%) in 1-year follow-up. All-cause mortality was $0.1 \%$ and $1.4 \%$ in 30-day and 1-year follow-up, respectively. In a 1-year follow-up patients hospitalized from $A F / A F l$ recurrence were more frequently hospitalized due to cardiovascular diseases other than $A F / A F l(9.6 \%$ vs. $6.7 \% ; p=0.026)$, especially due to hypertension (2.9\% vs. 0.7\%; $p<0.001$ ).
\end{abstract}

Conclusions: Over 1 out of 4 patients who underwent AF/AFl ablation were hospitalized due to arrhythmia recurrence in 1 year. (Cardiol J 2015; 22, 6: 630-636)

Key words: atrial fibrillation, ablation, pulmonary vein isolation

\section{Introduction}

Atrial fibrillation (AF), the most frequent sustained arrhythmia, is a growing clinical problem.
It is estimated that prevalence of AF will rise at least 2.5 -fold by the 2050 [1]. At the same time, the number of AF ablation procedures is increasing [2]. Despite the better patient selection and novel

Address for correspondence: Łukasz Januszkiewicz, MD, $1^{\text {st }}$ Chair and Department of Cardiology, Medical University of Warsaw, ul. Banacha 1a, 02-097 Warszawa, Poland, tel: +48 22599 19 58, fax: +48 2259919 57,

e-mail: lukasz.jan.januszkiewicz@gmail.com

Received: 03.04.2015 Accepted: 01.06.2015 
techniques, the effectiveness of this procedure is still unsatisfactory, resulting in a significant rate of $\mathrm{AF}$ recurrence and repeat ablation procedure [3].

Most of the data about follow-up of patients undergoing $\mathrm{AF}$ ablation derive from clinical trials conducted in selected centers with considerable experience in catheter procedures. However, it is well-known that clinical trial results do not represent well daily clinical practice, especially in the low volume, non-university centers. On the other hand, observational studies are often limited to single center observations of small populations. Moreover, there is a paucity of data regarding the recurrent hospitalization and repeat ablation in a routine practice. Therefore, there is clear need to establish multicenter or national registries which should provide accurate and robust data about $\mathrm{AF}$ ablation recipients.

The aim of the present study was to demonstrate the clinical evolution of $\mathrm{AF}$ ablation patients in Poland. We analyzed the follow-up of patients who were discharged after AF ablation procedure. We investigated $\mathrm{AF}$ recurrence, repeat $\mathrm{AF}$ ablation, hospitalization and mortality within 30 days and a 1-year follow-up after the index procedure using data from the Polish National Health Fund (NHF).

\section{Methods}

\section{Data sources}

Data on patients admitted to Polish hospitals for an atrial fibrillation/atrial flutter (AF/AFl) ablation procedure were derived from NHF. All admissions to Polish hospitals are registered in the Polish NHF. Admissions are coded with at least one primary diagnosis at discharge according to the International Classification of Diseases (ICD-10). The NHF holds information about the primary discharge diagnosis and procedures performed during hospitalization. Information on ablation procedure was retrieved from the National Patient Registry. All causes for hospitalizations are reported in order to get reimbursement from Polish NHF. Mortality derived from the national PESEL database (National Electronic System of Population Records). No data about patients' comorbidities before the index procedure were available.

\section{Study population}

Our study population comprised of all patients admitted to Polish hospitals with AF/AFl diagnosis (ICD-10 - I48) in order to perform procedure heart disturbances ablation with electroanatomical system (E41 according to Diagnosis Related Groups [DRG]) or AF balloon cryoablation (E45 according to DRG) in 2012. AF was diagnosed by the electrocardiogram (ECG) monitoring. Patients with $\mathrm{AFl}$ have the same ICD-10 code as AF patients (I48), and, therefore, AFl cases were included. AF management and ablation procedure were performed according to the current European Society of Cardiology guidelines [4]. All the patients were followed precisely for 1 year from discharge after the index procedure. No patient was lost to followup. Study protocol was approved by the Regional Ethics Committee. Index procedure was defined as first hospitalization in 2012 in order to perform $\mathrm{AF} / \mathrm{AFl}$ ablation with electroanatomical system or balloon cryoablation.

\section{Endpoints}

The primary endpoint was readmission to hospital with discharge diagnosis "atrial fibrillation/ /flutter". The secondary endpoints included: repeat $\mathrm{AF} / \mathrm{AFl}$ ablation, cardiovascular hospitalization, allcause hospitalization, all-cause mortality. Data on patient hospitalizations and survival were collected for 365 days. Each patient was observed for 1 year after discharge. All the endpoints were assessed in 30-day and a 1-year time frame. Cardiovascular hospitalizations were defined in accordance with DRG: E - heart disease, Q - vascular diseases and thromboembolic complications (stroke, venous thromboembolism). Hospitalizations due to coronary artery disease (including acute coronary syndromes), hypertension, heart failure (HF), and pacemaker implantation were recorded. AF/AFl hospitalizations were calculated separately.

\section{Statistics}

Continuous data are presented as mean \pm \pm standard deviation; those without normal distribution as median (interquartile range [IQR]). Categorical variables are presented as frequencies with percentages. Comparisons between groups were performed using a 2-tailed, paired or unpaired Student's $t$-test, U-Mann Whitney test for data with distribution other than normal, $\chi^{2}$-test and Fisher's exact test as applicable. A p $<0.05$ was considered statistically significant. Statistical analyses were performed in SPSS version 21.0 (SPSS Inc., Chicago, IL, USA).

\section{Results}

\section{Baseline characteristics}

We identified 2,022 patients from the NHF database who underwent $\mathrm{AF} / \mathrm{AFl}$ ablation between January 1, 2012, and December 31, 2012 in Poland. 
Approximately one third of the patients were female. The mean age was $58.6 \pm 10.9$ years. The mean time of the index ablation hospitalization was $3.8 \pm 2.6$ days. In 2012, 2,101 AF/AFl ablations were performed (1.04 procedure per patient). $\mathrm{AF} /$ $/ \mathrm{AFl}$ radiofrequency $(\mathrm{RF})$ ablation with electroanatomical system was performed in 1,552 $(76.8 \%)$ patients and $\mathrm{AF}$ cryoballoon ablation in $470(23.2 \%)$ patients. Follow-up time for all patients was 365 days. The baseline characteristics of the study group is presented in Table 1 .

\section{AF/AF1 hospitalization (primary endpoint)}

One hundred and twenty-three patients $(6.1 \%)$ were hospitalized due to $\mathrm{AF} / \mathrm{AFl}$ within 30 days. One hundred and nine were hospitalized once, 13 - twice, 1 - three times. There were 138 hospitalizations because of AF/AFl. AF/AFl was the most frequent discharge diagnosis in patients hospitalized within 30 days after the index hospitalization and it was present in $63.3 \%$.

In a 1-year follow-up, $540(26.7 \%)$ patients were hospitalized due to AF/AFl. Three hundred and fifty-one were hospitalized once, 108 patients - twice, $47-3$ times, 34 - at least 4 times. There were 879 hospitalizations because of AF/AFl (which contributed to $64.2 \%$ of all 1,369 hospitalizations in 1 year). $\mathrm{AF} / \mathrm{AFl}$ was the most frequent diagnosis at discharge in patients hospitalized within 1 year after the index hospitalization. Most frequent discharge diagnoses of rehospitalization are presented in Table 2 .

\section{AF/AF1 hospitalization vs. no AF/AF1 \\ hospitalization in a 1-year follow-up}

Five hundred and forty (26.7\%) patients were hospitalized with discharge diagnosis $\mathrm{AF} / \mathrm{AFl}$ within 1 year after the index hospitalization. There were no differences between this group and patients who were not rehospitalized with discharge diagnosis $\mathrm{AF} /$ /AFl in terms of age ( $58.21 \pm 10.87 \mathrm{vs.} 58.77 \pm 10.95$; $\mathrm{p}=0.35$ ) or gender (male $63.7 \%$ vs. $67.9 \% ; \mathrm{p}=0.07$ ) (Table 3 ). Index hospitalizations of patients rehospitalized due to $\mathrm{AF} / \mathrm{AFl}$ lasted longer $(4.06 \pm 2.5$ vs. $3.8 \pm 2.66$ days; $\mathrm{p}=0.001$ ). In 1-year follow-up, patients who were hospitalized because of $\mathrm{AF} / \mathrm{AFl}$ recurrence were also more frequently hospitalized due to other cardiovascular diseases than patients without subsequent $\mathrm{AF} / \mathrm{AFl}$ hospitalization (9.6\% vs. $6.7 \% ; \mathrm{p}=0.026)$. Recurrences of arrhythmia were as common after RF ablation as they were after cryoballoon ablation ( $27.3 \%$ vs. $24.8 \%$; $\mathrm{p}=$ $=0.311$ ). Patients rehospitalized because of $\mathrm{AF} /$ /AFl were more frequently hospitalized due to
Table 1. Baseline characteristics.

\begin{tabular}{lc}
\hline Number of patients & 2,022 \\
Males & $1,351(66.8 \%)$ \\
Mean age [years] & $58.6 \pm 10.9$ \\
Mean hospitalization time [days] & $3.8 \pm 2.6$ \\
Number of ablation in year 2012, & $2,102(1.04)$ \\
$\mathrm{n}$ (per patient): & $486(23.1 \%)$ \\
$\quad$ Cryoablation & $1,616(76.9 \%)$ \\
Radiofrequency ablation & 2,022 \\
Number of index ablation: & $470(23.2 \%)$ \\
$\quad$ Cryoablation & $1,552(76.8 \%)$ \\
$\quad$ Radiofrequency ablation & \\
\hline
\end{tabular}

Table 2. Discharge diagnosis in patients hospitalized in a 1-year follow-up.

\begin{tabular}{lc}
\hline $\begin{array}{l}\text { Number of patients hospitalized } \\
\text { in } 1 \text { year }\end{array}$ & $747(36.9 \%)$ \\
Number of patients hospitalized & \\
with discharge diagnosis: & \\
Atrial fibrillation/flutter & $540(26.7 \%)$ \\
Coronary artery disease: & $60(3.0 \%)$ \\
Treated interventionally & $35(1.7 \%)$ \\
Treated conservatively & $25(1.2 \%)$ \\
Heart failure & $51(2.5 \%)$ \\
Hypertension & $27(1.3 \%)$ \\
Vascular disease & $16(0.8 \%)$ \\
Thromboembolism: & $11(0.5 \%)$ \\
Stroke & $7(0.4 \%)$ \\
Venous thromboembolism & $4(0.2 \%)$ \\
\hline
\end{tabular}

hypertension (2.9\% vs. $0.7 \%$; $\mathrm{p}<0.001$ ). There were no differences between the groups regarding frequencies of hospitalization due to thromboembolism $(\mathrm{p}=0.185)$, stroke $(\mathrm{p}=0.11)$, coronary artery disease $(\mathrm{p}=0.378)$ or HF $(\mathrm{p}=0.446)$ in 1-year follow-up (Table 3).

\section{AF/AF1 hospitalization vs. no AF/AF1 hospitalization in 30-day observation}

We compared patients who were hospitalized due to $\mathrm{AF} / \mathrm{AFl}(\mathrm{n}=123)$ in 30 days with the rest of the population $(n=1,899)$. There were no differences regarding gender $(\mathrm{p}=0.07)$ or type of ablation $(p=0.756)$. There was no relation between AF/ /AFl hospitalization in 30 days and 1-year mortality ( $1.4 \%$ vs. $1.6 \% ; \mathrm{p}=0.854)$. Patients with $\mathrm{AF} / \mathrm{AFl}$ hospitalizations within 30 days of index ablation were more frequently hospitalized due to $\mathrm{HF}$ within 
Table 3. Comparison between atrial fibrillation/flutter (AF/AFI) hospitalization group and no AF/AFI hospitalization group in a 1-year follow-up.

\begin{tabular}{|c|c|c|c|}
\hline & $\begin{array}{c}\text { Hospitalization due } \\
\text { to AF/AFI group } \\
N=540(26.7 \%)\end{array}$ & $\begin{array}{l}\text { No hospitalizations } \\
\text { due to AF/AFI group } \\
N=1,482(73.3 \%)\end{array}$ & $\mathbf{P}$ \\
\hline Age & $58.2 \pm 10.9$ & $58.8 \pm 11.0$ & 0.35 \\
\hline Duration of the primary hospitalization & $4.06 \pm 2.5$ & $3.8 \pm 2.7$ & 0.001 \\
\hline Males & $344(63.7 \%)$ & $1,007(67.9 \%)$ & 0.07 \\
\hline Radiofrequency ablation & $423(78.3 \%)$ & $1,129(76.2 \%)$ & 0.311 \\
\hline Total mortality & $7(1.3 \%)$ & $22(1.5 \%)$ & 0.753 \\
\hline Strokes & $0(0 \%)$ & $7(0.5 \%)$ & 0.11 \\
\hline Thromboembolic events & $1(0.2 \%)$ & $10(0.7 \%)$ & 0.185 \\
\hline Heart failure hospitalizations & $16(3.0 \%)$ & $35(2.3 \%)$ & 0.446 \\
\hline Coronary disease hospitalizations & $19(3.5 \%)$ & $41(2.8 \%)$ & 0.378 \\
\hline Hypertension hospitalizations & $16(2.9 \%)$ & $11(0.7 \%)$ & $<0.001$ \\
\hline Vascular hospitalizations & $5(0.9 \%)$ & $11(0.7 \%)$ & 0.680 \\
\hline $\begin{array}{l}\text { Number of patients with cardiovascular } \\
\text { disease hospitalization (without AF/AFI) }\end{array}$ & $52(9.6 \%)$ & $99(6.7 \%)$ & 0.026 \\
\hline
\end{tabular}

1 year from ablation $(4.1 \%$ vs. $1.2 \% ; \mathrm{p}=0.006)$. Patients with AF/AFl hospitalizations within 30 days after the index hospitalization were more likely to undergo subsequent ablation within 1 year compared with the rest of the population $(22.8 \%$ vs. $8.6 \%$; $\mathrm{p}<0.001)$. The index hospitalization of patients who were hospitalized in 30 days because of $\mathrm{AF} / \mathrm{AFl}$ was longer than mean hospitalization time of the rest of the population $(4.42 \pm 2.83$ vs. $3.8 \pm 2.61 ; \mathrm{p}=0.003)$. There was a significant correlation between patients who were hospitalized because of $\mathrm{AF} / \mathrm{AFl}$ within 30 days and AF/AFl hospitalizations in 1 year $(\mathrm{r}=0.422 ; \mathrm{p}<0.001)$.

\section{Secondary endpoints}

During 30 days, 194 (9.6\%) patients were hospitalized regardless of the cause. One hundred and seventy-two patients were hospitalized once, 20 - twice and 2 - three times. In total, all-cause hospitalization number was 218 .

In 1-year follow-up, 747 patients were hospitalized regardless of cause (36.9\%). Four hundred and thirty patients were hospitalized once, $169-$ twice, $78-3$ times, $72-$ at least 4 times. There were 1,369 hospitalizations.

During a 1-year follow-up, 192 (9.5\%) patients underwent subsequent $\mathrm{AF} / \mathrm{AFl}$ ablations. In 165 $(86.0 \%)$ patients, 1 ablation was performed, in 26 patients - $2(13.5 \%)$ ablations, and in 1 patient $3(0.5 \%)$ ablations (Table 4$)$.
Table 4. Hospitalizations, repeat procedures and mortality.

\begin{tabular}{|c|c|}
\hline \multicolumn{2}{|l|}{ Hospitalizations } \\
\hline \multicolumn{2}{|l|}{30 day } \\
\hline Total number of hospitalizations & 218 \\
\hline Total number of patients hospitalized & $194(9.6 \%)$ \\
\hline \multicolumn{2}{|l|}{ Number of patients hospitalized: } \\
\hline once & 172 \\
\hline twice & 20 \\
\hline three times & 2 \\
\hline \multicolumn{2}{|l|}{1 year } \\
\hline Total number of hospitalizations & 1,369 \\
\hline Total number of patients hospitalized & $747(36.9 \%)$ \\
\hline $\begin{array}{l}\text { Number of patients hospitalized: } \\
\text { once }\end{array}$ & 430 \\
\hline twice & 169 \\
\hline three times & 78 \\
\hline at least four times & 72 \\
\hline \multicolumn{2}{|l|}{ Repeat atrial fibrillation/flutter ablations } \\
\hline $\begin{array}{l}\text { Number of repeat ablation } \\
\text { in } 1 \text {-year follow-up }\end{array}$ & $192(9.5 \%)$ \\
\hline Number of patients with: & $165(85.9 \%)$ \\
\hline \multicolumn{2}{|l|}{1 repeat ablation } \\
\hline 2 repeat ablation & $26(13.5 \%)$ \\
\hline 3 repeat ablation & $1(0.5 \%)$ \\
\hline \multicolumn{2}{|l|}{ Mortality } \\
\hline 30-day & $2(0.1 \%)$ \\
\hline 1-year & $29(1.4 \%)$ \\
\hline
\end{tabular}




\section{Mortality}

Twenty-nine (1.4\%) patients died during the follow-up. Two patients died within 30 days from the index hospitalization. First patient was a 65 -year-old male hospitalized 7 days during the index hospitalization. He died 22 days after discharge. He was not hospitalized in the follow-up. Second patient was a 68 -year-old male who was hospitalized 7 days during the index hospitalization. He was discharged to another center where he was hospitalized for 8 days because of AF/AFl. Sixteen days later he was admitted because of severe $\mathrm{HF}$ and he died 4 days after admission.

Patients who died in 1-year follow-up were older $(66.0 \pm 10.7$ vs. $58.5 \pm 10.9$ years; $p<0.001)$ and their index hospitalization lasted longer $(6.1 \pm 5.3 \mathrm{vs.}$ $3.8 \pm 2.6$ days; $\mathrm{p}=0.001$ ). The hospitalization due to $\mathrm{AF} / \mathrm{AFl}$ recurrence was not associated with higher 1 -year total mortality ( $1.3 \%$ vs. $1.5 \%$; $\mathrm{p}=0.753)$.

\section{Subgroup analysis}

Cryoballoon ablation vs. RF ablation. Cryoballoon ablation was performed in 470 (23.2\%) patients; RF ablation was performed in 1,552 $(76.8 \%)$ patients. No difference in mortality, total hospitalization rate and specific hospitalization type was observed except from the number of hospitalizations in 30-day follow-up because of thromboembolic events $(0.4 \%$ in cryoballoon ablation vs. $0 \%$ in $\mathrm{RF}$ ablation; $\mathrm{p}=0.01$ ).

Men vs. women. There were 671 women and 1,351 men included in the study. Men were younger than women $(57.3 \pm 11.1$ vs. $61.2 \pm 10.1$; $\mathrm{p}<0.001)$. Hypertension hospitalizations were more frequent in female patients $(2.2 \%$ vs. $0.9 \%$; $\mathrm{p}=0.013$ ). We observed a trend towards more frequent $\mathrm{AF} / \mathrm{AFl}$ hospitalization in 30-day followup and a 1-year follow-up in female patients than male patients $(7.5 \%$ vs. $5.4 \% ; \mathrm{p}=0.070 ; 29.2 \%$ vs. $25.5 \% ; \mathrm{p}=0.073)$. There were no differences regarding type of ablation $(\mathrm{p}=0.574)$, as far as other endpoints between the groups are concerned.

Repeat ablation vs. no repeat ablation. Among patients rehospitalized because of $\mathrm{AF} / \mathrm{AFl}$ $(\mathrm{n}=540)$, a comparison was made between the ones who underwent subsequent ablation within a years' time and the ones that did not. The patients who underwent another ablation were less frequently hospitalized due to $\mathrm{AF}$ in first 30 days $(28 / 191,14.7 \%$ vs. $95 / 349,27.2 \%$; $p=0.001)$ but more frequently in a years' time (364/191 vs. 524/349; $\mathrm{p}<0.001)$. They also had less hospitalization in general in first 30 days (34/191, 17.8\% vs. $106 / 349,30.4 \%$; $p=0.001$ ). The patients that underwent the second ablation were younger $(56.6 \pm 10.98$ vs. $59.11 \pm 10.83 ; p=0.019)$ and the time of the index hospitalization was shorter $(3.75 \pm 2.16$ vs. $4.45 \pm 3.26 ; \mathrm{p}=0.03)$. The type of initial ablation did not influence the decision about the second ablation $(\mathrm{p}=0.529)$. There were no differences regarding mortality $(2 / 191$, $1.0 \%$ in the repeat ablation group vs. $5 / 349,1.4 \%$ in the no repeat ablation group; $\mathrm{p}=0.705$ ). Out of 196 women with recurrence of arrhythmia, 54 underwent re-ablation and out of 344 men 137 had another procedure $(27.6 \%$ vs. $39.8 \%$; $\mathrm{p}=0.005)$.

\section{Multivariable analysis}

In a logistic regression model age, length of initial hospitalization, number of hospitalization in 1 year and all-cause hospitalization rate in 1 year influenced the risk of death but the model explained only $12.4 \%$ of observed differences. The probability of undergoing another ablation was influenced by age, sex, time of initial hospitalization, number of hospitalization due to $\mathrm{AF}$ in 30 days and in 1 year. This 5 -step model explained $13.5 \%$ of observed differences. An attempt to create a model predicting hospitalization in 1 year because of $\mathrm{AF}$ was made. With the factors included in this study only $1 \%$ of observed differences could be explained.

\section{Discussion}

In our large, unselected cohort of patients who underwent $\mathrm{RF}$ or cryoballoon $\mathrm{AF} / \mathrm{AFl}$ ablation in Poland in 2012, 26.7\% were hospitalized for AF/ $/ \mathrm{AFl}$ recurrence in a 1-year follow-up and $6.1 \%$ in 30-day follow-up. Close to $37 \%$ of patients were rehospitalized for any reason during 1 year and almost $10 \%$ during 30 -day period. These results show that a repeat ablation is required in almost a tenth of the population. We observed $1.4 \%$ death rate in a 1-year follow-up.

Our results are comparable with these reported in other registries [5, 6]. Shah et al. [5] identified $22 \% \mathrm{AF}$ readmission rate and almost $40 \%$ rehospitalization rate in $\mathrm{AF}$ ablation patients in California in a 1-year follow-up. In the same study, 30-day all-cause readmission rate was $10 \%$. In the J-CARAF study, ablation was successful in approximately $70 \%$ of paroxysmal $\mathrm{AF}$ patients and $60 \%$ of non-paroxysmal $\mathrm{AF}$ in a 1-year after the index procedure [6].

It should be assumed that the vast majority of hospitalization for arrhythmia recurrence was asso- 
ciated with symptomatic $\mathrm{AF} / \mathrm{AFl}$ and asymptomatic $\mathrm{AF}$ is highly prevalent [7]. Therefore, a real rate of $\mathrm{AF} / \mathrm{AFl}$ recurrence might be underestimated.

Prevalence of AF in general population is rising [1] and ablation procedures are more and more performed in symptomatic patients [2, 8], which is a result of widen indications to the procedure and a better availability of the ablation [4, 9]. It is worth to notice that $\mathrm{AF}$ ablation candidates are usually younger and have less comorbidities than general $\mathrm{AF}$ patients. This was also true in our cohort as the mean age of the studied population was 58.6 years and there were only 51 hospitalizations because of $\mathrm{HF}$ in the follow-up period. Apart from that, there is a clear demand on reduction the comorbidity rate, more effective arrhythmia treatment which might decrease the readmission rate of AF ablation recipients.

Longer duration of initial hospitalization was one of the risk factors for $\mathrm{AF} / \mathrm{AFl}$ rehospitalization. The initial ablation was less successful in patients who were hospitalized subsequently due to cardiovascular reasons. Patients with $\mathrm{AF} / \mathrm{AFl}$ hospitalizations within 30 days of index ablation were more frequently hospitalized due to HF within 1 year from ablation. Those results might point to the fact that patients with $\mathrm{AF} / \mathrm{AFl}$ recurrence after ablation have a greater burden of cardiovascular diseases especially hypertension and HF, which prolonged their initial hospitalization or that those disease are less successfully managed increasing the risk of $\mathrm{AF} / \mathrm{AFl}$ relapse. Patients with $\mathrm{AF} / \mathrm{AFl}$ hospitalization were more frequently hospitalized due to hypertension. This is also consistent with the fact that uncontrolled hypertension can promote AF.

It is worth noticing that patients who underwent repeat ablation within 1 year were younger and their initial hospitalization time was shorter. This might suggest that more attention should be paid in patient qualification for the ablation procedure. A screening for coronary artery disease and good control of HF risk factors as well as HF itself is highly needed. Interestingly, we observed gender discrepancies in making decision about reablation among patients with arrhythmia recurrence. Men underwent another ablation more frequently than women (39.8\% vs. $27.6 \%$; $p=0.005)$. One of the reasons explaining this phenomenon could be that women with recurrence of $\mathrm{AF} / \mathrm{AFl}$ had worse control of $\mathrm{AF} / \mathrm{AFl}$ risk factors. We observed that they were more frequently hospitalized due to hypertension in 1 year. In our population, women were older at the time of initial ablation. This fact could also influence the qualification for repeat ablation. Forleo et al. [10] reported that women undergoing AF ablation are older, have longer AF history and more comorbidities, however, they found no differences in $\mathrm{AF}$ recurrence compared with men. This observation is consistent with other results showing that women have higher rate of $\mathrm{AF} / \mathrm{AFl}$ recurrence after cardioversion [11]. This is interesting especially when compared with a suggestion of Kerr and Humphries [12] that successful interventional treatment might be particularly useful to improve the quality of life in women with AF.

\section{Limitations of the study}

The major limitation is the fact that our study group comprised of heterogeneous population of $\mathrm{AF}$ and AFl patients. The reason for this is that ICD-10 classification is used to report main discharge diagnosis (I48 - atrial fibrillation and flutter) to NHF. Therefore, we were unable to identify homogenous patients with AF only. The administrative data from NHF that were used in this study lacked the details that are available in clinical trials and registries like type of $\mathrm{AF}$, procedural technique, clinical course, medication usage, especially antithrombotic treatment, and comorbidities. However, this limitation was counterbalanced by the fact that our data were not associated with a single center experience and allowed for the inclusion of more patients, especially ones who are not usually well represented in clinical trials. Moreover, we did not obtain data on previous $\mathrm{AF}$ ablation procedures. We did not incorporate typical 3-month blanking period used in clinical trials of AF patients undergoing catheter ablation, because aim of our study was to present all readmissions to hospital.

\section{Conclusions}

Over a 1 out of 4 patients who underwent AF/ /AFl ablation was hospitalized because of arrhythmia recurrence in 1 year. Over one-third ablation recipients were hospitalized in 1-year follow-up. Almost $10 \%$ of all ablation patients underwent subsequent ablation within a year from the initial procedure. Patients qualified for another ablation procedure were younger and the time of the index hospitalization was shorter. Future studies should focus on novel methods of reducing arrhythmia recurrence and readmissions.

\section{Conflict of interest: None declared}




\section{References}

1. Go AS, Hylek EM, Phillips KA et al. Prevalence of diagnosed atrial fibrillation in adults: National implications for rhythm management and stroke prevention: The anticoagulation and risk factors in atrial fibrillation (atria) study. JAMA, 2001; 285: 2370-2375.

2. Kumar S, Walters TE, Halloran K et al. Ten-year trends in the use of catheter ablation for treatment of atrial fibrillation vs. The use of coronary intervention for the treatment of ischaemic heart disease in australia. Europace, 2013; 15: 1702-1709. doi: 10.1093/europace/eut162.

3. Cappato R, Calkins H, Chen SA et al. Updated worldwide survey on the methods, efficacy, and safety of catheter ablation for human atrial fibrillation. Circ Arrhythm Electrophysiol, 2010; 3: 32-38. doi: 10.1161/circep.109.859116.

4. Camm AJ, Kirchhof P, Lip GY et al. Guidelines ESCCfP. Guidelines for the management of atrial fibrillation: The task force for the management of atrial fibrillation of the European Society of Cardiology (ESC). Europace, 2010; 12: 1360-1420. doi: 10.1093/ europace/euq350.

5. Shah RU, Freeman JV, Shilane D, Wang PJ, Go AS, Hlatky MA. Procedural complications, rehospitalizations, and repeat procedures after catheter ablation for atrial fibrillation. J Am Coll Cardiol, 2012; 59: 143-149. doi: 10.1016/j.jacc.2011.08.068.

6. Murakawa Y, Nogami A, Shoda M et al. Nationwide survey of catheter ablation for atrial fibrillation: The japanese catheter ablation registry of atrial fibrillation (j-caraf): Report of 1-year follow-up. Circ J, 2014; 78: 1091-1096. doi: 10.1253/circj.CJ-14-0099.

7. Lip GY, Laroche C, Ioachim PM et al. Prognosis and treatment of atrial fibrillation patients by european cardiologists: One year follow-up of the eurobservational research programme-atrial fibrillation general registry pilot phase (eorp-af pilot registry). Eur Heart J, 2014; 35: 3365-3376. doi: 10.1093/eurheartj/ehu374.

8. Ferrero de Loma-Osorio A, Gil-Ortega I, Pedrote-Martinez A, Spanish Catheter Ablation Registry. Spanish catheter ablation registry. 13th official report of the spanish society of cardiology working group on electrophysiology and arrhythmias (2013). Rev Esp Cardiol, 2014; 67: 925-935. doi: 10.1016/j.rec.2014.07.009.

9. Ellis ER, Culler SD, Simon AW, Reynolds MR. Trends in utilization and complications of catheter ablation for atrial fibrillation in medicare beneficiaries. Heart Rhythm, 2009; 6: 1267-127. doi: 10.1016/j.hrthm.2009.06.009.

10. Forleo GB, Tondo C, De Luca L et al. Gender-related differences in catheter ablation of atrial fibrillation. Europace, 2007; 9: 613-620. doi: 10.1093/europace/eum144.

11. Suttorp MJ, Kingma JH, Koomen EM, van't Hof A, Tijssen JG, Lie KI. Recurrence of paroxysmal atrial fibrillation or flutter after successful cardioversion in patients with normal left ventricular function. Am J Cardiol, 1993; 71: 710-713.

12. Kerr CR, Humphries K. Gender-related differences in atrial fibrillation. J Am Coll Cardiol, 2005; 46: 1307-1308. doi: 10.1016/j. jacc.2005.07.007. 